\title{
RESENHA DO LIVRO “HIBRIDISMO CULTURAL” DE PETER BURKE
}

\author{
BURKE, Peter. Hibridismo Cultural. São Leopoldo: Ed. Unisinos, 2006.
}

\author{
Anderson Lopes da Silva ${ }^{1}$
}

Peter Burke nasceu em 1937, em Stanmore, no subúrbio de Londres (Reino Unido). O historiador, que possui doutorado pela Universidade de Oxford, começou sua carreira acadêmica na Universidade de Sussex, na Inglaterra, e atualmente leciona na Universidade de Cambridge. É reconhecido internacionalmente pelos temas ligados à História da Cultura e, especialmente, por sua abordagem historiográfica sociocultural acerca do Brasil e alguns pensadores como Gilberto Freyre. Burke também foi professor-visitante na Universidade de São Paulo durante os anos de 1994-1995.

O historiador cultural apresenta, em tom de ensaio, uma literatura que pode ser considerada básica, didática e, por isso mesmo, hipertextual. Esta última característica se deve principalmente pela reiteração de alguns autores dos Estudos Culturais trabalhados em Burke (como Stuart Hall, Homi Bhabha e Nestór García Canclini) e o direcionamento que ele oferece ao leitor para potenciais aprofundamentos. Durante toda obra o enfoque do autor inglês detém-se sobre a ideia de "variedade", sob uma perspectiva histórica, que tenta analisar a "mistura", a "mixórdia", ao invés de replicá-la tão somente (2006, p. 21).

Na obra "Hibridismo Cultural" (2006), o autor apresenta a temática a partir de uma divisão que diz respeito às várias formas de leitura da hibridização: a) seja pela variedade de objetos considerados híbridos; b) pelas nomenclaturas utilizadas para a descrição do processo; c) pelas distintas situações nas quais as ocorrências híbridas são potenciais; d) as reações possíveis à hibridização; e, por fim, e) os resultados destes processos numa perspectiva de longo prazo.

Acerca da variedade de objetos híbridos, Burke é cauteloso em explicitar o lugar de onde fala. Assim, ao apresentar as três subdivisões dos objetos, isto é, os artefatos, práticas e povos híbridos, o autor deixa claro que o sentido dos processos híbridos não pode ser considerado sinonímico em sua ocorrência nas religiões sincréticas, nas línguas híbridas, nas culinárias mestiças, nos estilos literários que se misturam, nas filosofias de abordagem eclética, na arquitetura, na música e em outras formas. Em cada espaço social e histórico essas ocorrências possuem sentidos distintos.

Assim, ele trata dos artefatos híbridos apresentando exemplos da arquitetura, das imagens de culto e de gravuras, além dos textos e sua estilística que passam por processos de mistura em dois níveis. O primeiro está relacionado aos "estereótipos ou esquemas culturais" presentes na estrutura da percepção e interpretação do mundo (que são acionados no momento da construção destes) e o segundo relacionado às "afinidades ou convergências" de distintas tradições, nas quais a origem do artefato híbrido pode possuir semelhanças comungadas pela sua representação e sentido nos espaços sociais de sua produção (BURKE, 2006, p. 26). Um aspecto que merece destaque, segundo o autor, é que nos artefatos híbridos é possível perceber características de inovação, efeitos equivalentes e assimilações e uma total recusa à imitação pura e simples (BURKE, 2006, p. 27-28).

Por sua vez, as práticas culturais híbridas também podem ser identificadas na música, na religião, na linguagem, no esporte e nas festividades a partir das relações entre as instituições e as pessoas. Fica nítida a correlação entre o conceito de hibridização para Burke e pelo pesquisador indiano Homi Bhabha, baseando-se na inter-relação identidade, representação social e linguagem. Para Bhabha só é possível entender as representações criadas acerca da hibridização a partir da esfera do discurso, em outras palavras, é na linguagem que se encontram os caminhos desenhados pela identidade híbrida e mestiça. Outros

1 Mestrando em Comunicação pela Universidade Federal do Paraná (PPGCOM / UFPR). Especialista em Comunicação, Cultura e Arte (PUCPR) e Jornalista (FACNOPAR). Bolsista da Capes. E-mail: anderlopps@gmail.com. 
exemplos dados pelo autor inglês como práticas culturais são o carnaval brasileiro, as igrejas e as formações religiosas que se apropriam de diversas formas de culto, ícones e filosofias (BURKE, 2006, p. 28-35).

Já a variedade de objetos que diz respeito aos povos híbridos está mais ligada à figura do híbrido como um mediador cultural e as formas de representação social dos que "nascem híbridos", isto é, aqueles que já nascem com uma consciência dúplice, os frutos de dois ou mais povos e que, por isso, possuem uma relação extremamente peculiar com sua origem e identidade.

Como exemplo de correlação entre visões sobre a hibridização é possível ver em Burke a variedade de povos híbridos quando este apresenta os anglo-irlandeses, os anglo-indianos, os afro-americanos, os sino-americanos, os gregos de Constantinopla e os judeus e mulçumanos que viveram em Andaluzia (Espanha). A esta visão, pode-se acrescentar a leitura que o jamaicano e teórico da cultura Stuart Hall faz dos sujeitos que migram de seus países - como no exemplo daquele que sai de uma ex-colônia para o antigo país colonizador - e que começam a viver experiências que já não os "classificam" como indivíduos estrangeiros e nem como nativos, mas sim como híbridos pós-coloniais.

A variedade de terminologias usadas para a descrição dos processos de interação e consequências da hibridização cultural são, ao contrário dos artefatos, nomenclaturas que representam um mesmo valor semântico. Segundo o historiador inglês, as metáforas que dominam as discussões acerca da hibridização são advindas de outros campos (como economia, linguística e biologia): empréstimo, hibridismo, caldeirão cultural, ensopadinho cultural, tradução cultural e crioulização.

Entretanto, mesmo que tenham significados correlatos, cada uma das terminologias pode referir-se a processos específicos de hibridização cultural como a imitação e a apropriação cultural; a acomodação e a negociação; a mistura, o sincretismo e a hibridização e, finalmente, a tradução cultural (BURKE, 2006, p.39-54). No nível discursivo esta variedade de termos pode referir-se ora a um viés mais descritivo e explicativo, ora a um viés no qual o agente individual ou as ações coletivas são capazes de promover a hibridização. Além disso, novos sentidos começam a ser dados a termos como "mestiçagem", que era entendida preconceituosamente por dar origem a sujeitos "bastardos" ou de "fecundação-cruzada", mas que, hoje, já possui uma conotação que se descolou da carga pejorativa (BURKE, 2006, p. 51).

As situações nas quais a hibridização cultural pode ocorrer são apresentadas pelo autor a partir de quatro pressupostos básicos, elencadas na seguinte ordem: a noção de iguais e desiguais (ligada principalmente às relações de poder nas quais o mais "forte" impõe sua forma de cultura, ainda que existam elementos que assegurem a resistência dos mais "fracos"); a ideia das tradições de apropriação, também chamadas de tradições de modificação de tradições (aqui há variados níveis de aceitação e adaptação por parte do embate entre as culturas); há também a discussão acerca da situação entre a metrópole e as regiões ao redor (em especial sobre a questão das trocas culturais entre centro e periferia) e fronteiras (o choque entre culturas diferentes promove elementos híbridos que são lidos pelo olhar das interculturas); e a concepção de classe como culturas, isto é, a situação na qual mais uma vez o poder relacional e a luta de classes, com destaque para processos de resistência e consensualidade, são estimuladores da hibridização (BURKE, 2006, p. 65-75). Acerca desses fatores é interessante observar que o que antropólogo argentino García Canclini entende por hibridização cultural - como o desmoronamento da separação entre cultura popular, erudita e massiva - relaciona-se perfeitamente com a visão de Burke acerca das ideias compartilhadas por ambos sobre as redes transfronteiriças de cultura e troca de símbolos.

Ao falar das reações aos processos hibridizadores, Peter Burke pergunta: “A troca é uma consequência dos encontros: mas quais são as consequências da troca?" (2006, p. 77). A resposta à indagação pode ser descrita em quatro principais reações: a aceitação, a rejeição, a segregação e a adaptação. A reação de aceitação à hibridização é exemplificada pelo autor como a "londonização cultural" do Brasil no início do século XIX (BURKE, 2006, p. 95), em que costumes, vestimentas e valores da zona temperada eram transpostos para a zona tropical (sempre por interações culturais que conseguem harmonizar o conflito e, por fim, a aceitação). A rejeição é esclarecida através da resistência ao diferente, da estratégia de defesa contra a invasão das fronteiras culturais 
e por uma "purificação cultural" (entretanto, de acordo com o autor, também existe aqui a valoração positiva da rejeição, aquela que - por meio da educação - tenta manter a cultura oral, as tradições e outros elementos que a constituem frente à ideia de uma cultura globalizada) (BURKE, 2006, p. 80-86).

A reação de segregação ocorre quando tudo o que é distinto da cultura local é visto como ameaçador e evitam todas as formas - mesmo que em franca desvantagem - de hibridização com um potencial "mosaico cultural" (BURKE, 2006, p. 88). A tendência, de acordo com Burke, é que a segregação radical venha, com o tempo, a transformar-se em adaptação e negociação, ou seja, "um empréstimo no varejo para as partes em uma estrutura tradicional" que descontextualiza e recontextualiza (2006, p. 91) o objeto original para uma nova significação em sua cultura (como a "tropicalização" brasileira da culinária, arquitetura e vestimentas de outros países e seus imigrantes). A metáfora da circularidade ("reexportação" do item hibridizado ao local de origem) e o papel dos tradutores (e a necessidade da equivalência sócio-semântica para o exercício da profissão) encaixam-se na reação adaptativa (BURKE, 2006, p. 94-97).
Por fim, os resultados possíveis de longo prazo esperados da hibridização cultural, de acordo com Peter Burke, são direcionados pela quase "erradicação" das chamadas culturas insulares, isto é, nenhuma cultura pode sobreviver sem interações com o diferente (BURKE, 2006, p. 101).

Tais resultados podem ser descritos em quatro cenários (BURKE, 2006, p. 103-115): como a contraglobalização (uma ênfase na identidade local e forte tendência à rejeição às culturas externas, aos sujeitos e seus modos de vida); a diglossia cultural (presença e quase exigência do bilinguismo cultural, em especial nas zonas fronteiriças); a homogeinização da cultura (aqui as ideias de imperialismo cultural são parecidas à homogeinização, entretanto, a produção de hibridização já começa pela "glocalização") e o cenário da hibridização com a metáfora da "crioulização" e sua abertura às novas culturas, à reconfiguração dos elementos já existentes e à criação fluida de ambientes híbridos peculiares.

Recebido em fevereiro de 2014 Aceito em abril de 2014 